\title{
Experimental study of multicomponent diffusion in low permeable sediments
}

\author{
Vladimir Lekhov ${ }^{1, *}$, Alexei Lekhov ${ }^{1}$ \\ ${ }^{1}$ Faculty of Geology, Department of Hydrogeology, Lomonosov Moscow State University, GSP-1, \\ Leninskie Gory, Moscow 119899, Russia
}

\begin{abstract}
Diffusion coefficients for $\mathrm{Na}^{+}$and distribution coefficients for $\mathrm{Cs}^{+}, \mathrm{Ba}^{2+}, \mathrm{Ni}^{2+}, \mathrm{CO}^{2+}, \mathrm{Sr}^{2+}$ were measured on low permeable samples (3 $\mathrm{cm}$ diameter, average length $7 \mathrm{~cm}$ ) from the deep disposal site Siberian Chemical Combine (SSC) using the end-diffusion technique. The direction of diffusion was perpendicular to bedding. Special equipment for experiment were designed and constructed. Two types of concentration observation were used. For non-sorbing $\mathrm{Na}^{+}$in time used EC sensors and length distribution of sorbed elements. The synthetic solution used in the experiments was a model of low-activity contaminant of the SSC, and consist $\mathrm{NaNO}_{3}(25 \mathrm{~g} / \mathrm{l})$ and nitrate compounds: $\mathrm{Cs}^{+}, \mathrm{Ba}^{2+}, \mathrm{Ni}^{2+}, \mathrm{Co}^{2+}, \mathrm{Sr}^{2+}$ $(100 \mathrm{mg} / \mathrm{l}$ each). The measured values of the effective diffusion coefficients $D_{\mathrm{e}}$ ) for $\mathrm{Na}^{+}$from $7.60 \times 10^{-7}$ to $1.51 \times 10^{-5} \mathrm{~m}^{2} /$ day and volumetric dimensionless distribution coefficients $\left(K_{d} \rho\right)$ are: $\mathrm{Cs}^{+}$ from 0.21 to $22.1, \mathrm{Ba}^{2+}$ from 1.1 to $1.45, \mathrm{Ni}^{2+}$ from 0.3 to $16.4, \mathrm{Co}^{2+}$ from 1.98 to $24.7, \mathrm{Sr}^{2+}$ from 1.9 to 14.3 . The values of the diffusion coefficient show a large degree of variability. The diffusion coefficients of nonsorbing $\mathrm{Na}^{+}$measured in this study are in good agreement with pore-scale diffusion simulation on microtomography data.
\end{abstract}

\section{Introduction}

The actual estimating method of liquid radioactive waste disposal safety is mathematical modeling, which requires regional numerical flow and transport models. Such models can be used to forecast contaminant transport. Such models were developed for SSC site $[1,2]$, and improving them by upgrading the validity of the transport parameters used in them is the most important task.

Obtaining relevant forecasts to a large extent depends on taking into account the details of the flow heterogeneity of the polygon and physical and chemical processes during the contaminant transport. To take into account the latter, it is necessary to have reliable parameters of transport properties of the studied sediment types, which usually hards to diagnose due to high complexity and cost of their determination, but use characteristic values for similar rocks, given in the literature.

\footnotetext{
* Corresponding author: v.lekhov@gmail.com
} 
Based on the analysis of published experimental determinations obtained by different authors, it should be noted that the maximum established diffusion coefficient differs by four orders from a minimal. That indicates the impossibility of using these parameters for simulation, based only on the literature data. The reason for such a wide range in the diffusion coefficient is its dependence on the microstructure of sediments (active porosity, tortuosity) [3].

Therefore, in order to create an adequate transport model for the long-term transport of radioactive waste and to obtain a result that correctly takes into account the influence of diffusion in low-permeability rocks, it is necessary to carry out experimental determination of the parameters that determine the diffusion transport.

\section{Materials and methods}

\subsection{Experiment conception}

Analysis of the published literature on experimental determination of diffusion and distribution coefficients [3,4] the model of diffusion experiment is developed with a multicomponent solution consisting of a non-active tracer - the main salt, and sorbed microcomponents (Fig. 1). Because of the different rate of diffusion of sorbed and nonsorbing components it was proposed to use two types of observations: continuous $(x=$ const) in time, recording the change in the concentration of the main salt at several points along the length of the sample by measuring the electrical conductivity in situ, and discrete $(t=$ const $)$ - the distribution of concentrations of all sorbed elements along the length, obtained after the experiment. Equating the concentrations of the neutral component in the diffusive solution with the concentrations of the component in the sample at the end of the diffusion mass transfer, the active porosity $n_{\mathrm{a}}$ was obtained. As a result, the pore diffusion coefficient $\left(D / n_{\mathrm{a}}\right)$ of the non-sorbed component is determined on continuous data, and the pore diffusion coefficients $\left(D /\left(n_{a}+K_{d}^{i} \rho\right)\right)$ of the sorbed elements are determined on the discrete data, from which, assuming that sorption is carried out on Henry's isotherm, distribution coefficients $K_{\mathrm{d}}$ was obtained.

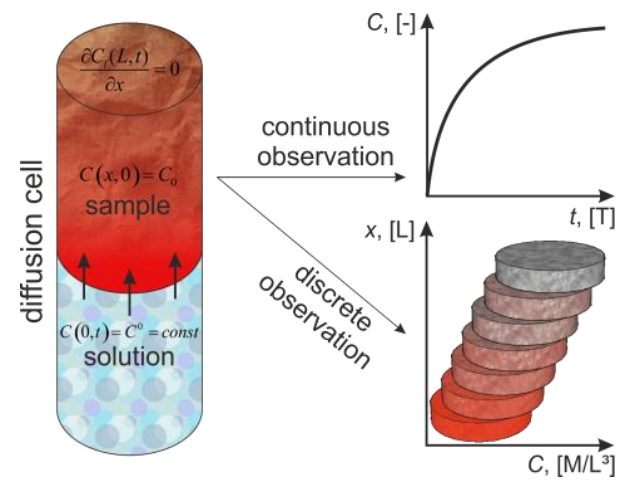

Fig. 1. Basic scheme of diffusion experiment and types of observations used.

\subsection{Sample preparation}

For the experimental studies 16 samples of undisturbed structure were used, taken in the area of SSC from the depth of 200-400 m from the cores of monitoring wells drilled in recent years. For each sample, the grain size distribution, mineral composition, skeleton 
density and solids density were determined, and the microstructure was quantitatively analyzed using scanning electron microscopy (SEM) and X-ray microtomography ( $\mu \mathrm{KT})$. The mineral composition was determined by X-ray diffraction quantitative analysis. The content of primary minerals (quartz, feldspars) varies from 40 to $60 \%$. The content of kaolinite $10-35 \%$ and low content of smectite indicate the continental origin of the samples under study. The total amount of clay minerals in the samples varies from 35 to $55 \%$.

Samples are solid cylinders with a diameter of $3 \mathrm{~cm}$ and a height of 5 to $8 \mathrm{~cm}$, cut from the obtained cores. In the experiments, the outside cylindrical surface of the samples was covered with epoxy resin to prevent wall flow and diffusion, and threaded connections were glued to the lower and upper ends.

\subsubsection{Continuous measurement}

Registration of the tracer during the diffusion experiment was made with the 4 electrode sensors connected to the EC meter «Expert - 002», installed along the length of the sample in synthetic holes imitating large pores. The sensors are made of audio connectors «jack 2.5 $\mathrm{mm} \gg$ and are installed in drilled cells with a $2 \mathrm{~mm}$ spacing. For autonomous sampling and saving the current readings EC, a switchboard was designed and assembled with the ability to connect 50 sensors and transfer data to a portable computer with a specified frequency.

\subsection{Experimental set up}

The experimental set up is designed and assembled from PFC fittings and sanitary parts. The samples were saturated with distilled water through the lower end. For this purpose, $200 \mathrm{~cm}$ long polypropylene tube connected to a piezometer was used. To accelerate the saturation process and to avoid the formation of compressed air, a vacuum of 0.15 mbar was created at the upper end of the sample. Saturation was applied before water on the top face of the sample came into being. The average saturation time was 10 days.

At the end of saturation, the hydraulic conductivity $k$ was determined in a non-stationary mode with falling head method. At the end of the hydraulic conductivity experiment the upper end of the sample was covered with paraffin to prevent evaporation in the process of next diffusion experiment.

\subsection{Experimental determination of diffusion coefficients and distribution coefficient}

Following the hydraulic conductivity experiment, a diffusion experiment with constant in time boundary conditions was made: constant concentration at the lower end of the sample and impermeable boundary at the upper end. In preparation of the experimental set up for the transport experiment, a polypropylene tube was disconnected from the piezometer and the tank was loaded with a specially prepared solution imitating the wastes pumped into the SSC.

Before the experiment started, air was removed from the experimental setup and the level in the piezometer was set to the height of the sample to compensate for the pressure in the system, thus avoiding drying the sample during the experiment. In the experiment, the diffusion solution in the tank was not changed, but only mixed once every three days. As the tank volume is about 100 time larger than the sample porous volume, the mass leaving the solution $(1-1,5 \%)$ was ignored during the experiment.

During the experiment on each sensor the change of EC of solution and temperature in the laboratory every 30 minutes was saved. At the end of the experiment the samples were cut perpendicularly to the axis of the cylinder into $1 \mathrm{~cm}$ thick discs. Determination of concentrations of $\mathrm{Na}^{+}$by length was performed by flame photometry method on water 
extracted from the discs. To obtain the ratio of the concentration of the sorbed elements to the length, the content of $\mathrm{Cs}^{+}, \mathrm{Ba}^{2+}, \mathrm{Ni}^{2+}, \mathrm{Co}^{2+}, \mathrm{Sr}^{2+}$ in the discs on the wave $\mathrm{X}$-ray fluorescent analyzer (XRF) was measured. For the studied cations the background concentrations were determined by the same methods in the core fragments.

\section{Diffusion transport model}

According to the design of the experimental set up applied, the one-dimensional diffusion process going on in the samples for each component can be characterized by the diffusion model with equilibrium sorption [5] in a sample of limited length with an impermeable upper boundary and a lower boundary with a constant concentration:

$$
D^{i} \frac{\partial^{2} C^{i}}{\partial x^{2}}=\left(n_{a}+K_{d}^{i} \rho\right) \frac{\partial C^{i}}{\partial t}, \quad C^{i}(0, t)=C^{i 0}, C^{i}(x, 0)=C_{0}^{i} ; \frac{\partial C^{i}(L, t)}{\partial x}=0
$$

where $C^{i}$ - concentration, $D^{i}$ - effective diffusion coefficient, $K_{d}^{i}$ - distribution coefficient of $i$-th cation $(i=1 \div 6), n_{a}$ - effective transport-through porosity, $\rho$ - bulk density of porous media, the term $\left(n_{a}+K_{d}^{i} \rho\right)$ is also known as the capacity factor.

It should be noted that the macrocomponent $(i=1) \mathrm{Na}^{+}$is a sorbed cation by the isotherm of Legmyur's type. Its concentration at the boundary $(5.4 \mathrm{~g} / \mathrm{l})$ is much higher than the sorption capacity of the studied sediments, so in a wide range of relative concentrations it can be considered as non-sorbing, because its calculated $K_{d}$ aims to zero. However, it occupies a large part of the sorption capacity of the rock in the process of diffusion. Therefore, it is supposed that the sorption of other microcomponent cations against the background of the sorbed $\mathrm{Na}^{+}$takes place according to Henry's law with a constant value of $K_{d}^{i}$.

At the given initial and boundary conditions and hypotheses made about the distribution $K_{d}$, the solution of equation (1) has the form [6]:

$$
\bar{C}^{i}(x, t)=\frac{C^{i}(x, t)-C_{0}^{i}}{C^{i 0}-C_{0}^{i}}=\sum_{j=1}^{\infty} \frac{2}{p_{j}}(-1)^{j+1} \cos p_{j} \frac{L-x}{L} \exp \left(-p_{j}^{2} \frac{D^{i} t}{n_{e}^{i} L^{2}}\right), p_{j}=(2 j-1) \frac{\pi}{2}
$$

where $L$ - length of the model, $x$ - distance to the border with a constant concentration, $t$ time. According to this solution, using the output curves of concentration changes in time by sensors and distribution of concentration along the length to the end of the experiment, one can find a pore diffusion coefficient of $D / n$ for a non-sorbing $\mathrm{Na}^{+}$(Fig. 2 left), and $D^{i} / n^{i}$ for each sorbed microcomponent: $\mathrm{Cs}^{+}, \mathrm{Ba}^{2+}, \mathrm{Ni}^{2+}, \mathrm{Co}^{2+}, \mathrm{Sr}^{2+}$. Temperature correction was applied to the EC data. Changing the effective transport-through porosity $n_{a}$, the concentration in the first disk equal to the concentration of $\mathrm{Na}^{+}$in the solution was matched. (Fig. 2 right)
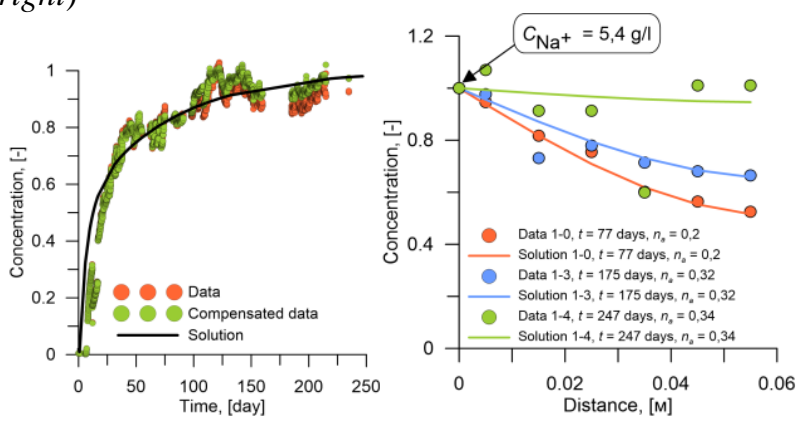

Fig. 2. Difference of experimental data without temperature compensation and with temperature compensation for the second sensor of the sample 1-4 (left); Selection of active porosity through $\mathrm{Na}^{+}$ concentration at the sample boundary (right). 


\section{Results and conclusions}

The obtained values of hydraulic conductivity $k$ are in the range $(2.2-7.7) \times 10^{-5} \mathrm{~m} /$ day. The correlation of porosity with the obtained experimental values of $k$, as well as the correlation with grain size distribution and mineralogical compositions was not found.

The transport experiments were performed with a duration of 77 to 247 days. Using data on the temperature in the laboratory for the full period of the experiment, temperature correction was done for each sensor. The diffusion coefficient of $\mathrm{Na}^{+}$by $\mathrm{EC}$ sensors and concentration distributions by sample length was from $7.60 \times 10^{-7}$ to $1.51 \times 10^{-5} \mathrm{~m}^{2} /$ day, with effective transport-through porosity of the samples under study $0.13-0.4$, which is from 45 to $90 \%$ of their total porosity.

The volumetric distribution coefficients (dimensionless) for the analyzed elements were: $\mathrm{Cs}^{+}$from 0.21 to $22.1, \mathrm{Ba}^{2+}$ from 1.1 to $1.45, \mathrm{Ni}^{2+}$ from 0.3 to $16.4, \mathrm{Co}^{2+}$ from 1.98 to 24.7, $\mathrm{Sr}^{2+}$ from 1.9 to 14.3 . At calculation, the effective diffusion coefficient of a microcomponent was corrected on the basis of the ratio of effective diffusion coefficient of a certain component to $\mathrm{NaNO}_{3}$ on the basis of the reference data. The obtained relatively small values of volumetric $K_{\mathrm{d}}$ mainly 10 for microcomponents can be explained by the large amount of $\mathrm{Na}^{+}$, which, as has already been said, are strong candidates in the occupation of active centers by the dominant concentration.

The reported study was funded by RFBR according to the research project № 18-35-00460.

\section{References}

1. V.M. Shestakov, A.A. Kuvaev, A.V. Lekhov, S.P. Pozdniakov, A.I. Rybalchenko, A.V. Zubkov, P.A. Davis, E.A. Kalinina, Environ. Geol., vol. 42, no. 2-3, pp. 214-221, (2002)

2. M.L. Glinskii, S.P. Pozdnyakov, L.G. Chertkova, A.A. Zubkov, V.V. Danilov, V.A. Bakshevskaya, V.N. Samartsev, Radiokhimiya, vol. 56, no. 6, pp. 554-560, (2014)

3. T.B. Boving, P.J. Grathwohl, Contam. Hydrol., vol. 53, no 1-2, pp. 85-100, (2001)

4. F.S. Barone, R.K. Rowe, R.M. Quigley, J. Geotech. Eng., vol. 118, no. 7, pp. 10311045, (1992)

5. A.A. Roshal, Metody opredeleniya migratsionnykh parametrov (VIEMS review, Hydrogeology and engineering geology series, Moscow, 1980)

6. A.V. Lykov, Teoriya teploprovodnosti (Vysshaya shkola Publ., Moscow, 1967) 